\title{
Breakfast habits and heath perceptions in South-eastern Spanish adolescents
}

\author{
Encarnación Soriano-Ayala ${ }^{1 a}$, Verónica C. Cala ${ }^{1}$, Antonio J. González-Jiménez ${ }^{1}$, Diego \\ Ruiz Salvador and y Clemente Franco Justo ${ }^{1}$ \\ ${ }^{1}$ Univesity of Almería, Ctra. Sacramento, S/N, Almería, 04120, Spain
}

\begin{abstract}
The principal aims of this study are to describe breakfast consumption patterns of south-eastern Spanish adolescents, examine the relationship between breakfast consumption and feelings of well-being and fitness and compare breakfast behaviour between men and women to identify if there is a gender gap. Design: A cross-sectional research with cluster sampling in two primary schools and seven secondary schools. The instrument used was a modified version of the Kidscreen-27 questionnaire. Sample: 2,125 students aged between 10 and 19 years old from different nationalities, mainly Romanian, Moroccan and Spanish. Results: The study identifies some youngsters who skip breakfast and no have no food intake over the course of the morning. About $35 \%$ of the teenagers skip daily breakfast before they leave for school, and a worrying $1,8 \%$ do not eat any food during the whole morning. Questionnaire outcomes also expresses that the amount of biscuits ingested increased as the number of times that adolescents have breakfast at home decreases. There are significant gender differences, women it less foods than men. Differences are especially significant in case of milk, bread or cereals and butter or oil. Finally, chisquare contrast analysis show students that have breakfast before leaving to school perceive better feelings about how well and fit they are than those student who do not have breakfast daily. Conclusions. Findings supports the need for further enhance health education programs focused on breakfast habits, especially with women. This study is part of the project "Education for Cross-cultural Health in Immigrant and Native Adolescents from Almeria: Analysis and intervention for optimization and improvement" supported by the National R+D Plan of the Ministry of Economy and Finance (Ref: EDU2011-26887)
\end{abstract}

Keywords : Transcultural health; breakfast; adolescents; gender gap.

${ }^{a}$ Corresponding author: esoriano@ual.es

(C) The Authors, published by EDP Sciences. This is an open access article distributed under the terms of the Creative Commons Attribution License 4.0 (http://creativecommons.org/licenses/by/4.0/). 


\section{Introduction}

Here introduce the paper, and put a nomenclature if necessary, in a box with the same font size as the rest of the paper. The paragraphs continue from here and are only separated by headings, subheadings, images and formulae. The section headings are arranged by numbers, bold and $10 \mathrm{pt}$. Here follows further instructions for authors.

Adolescence is a crucial period for the construction and development of healthy lifestyles. Maintaining proper eating habits and having a structured dietary behaviour during childhood and adolescence that includes having breakfast can help to prevent chronic diseases later in life (diabetes, cancer, cardiovascular diseases) and contributes to psycho-emotional well-being, [6]. Breakfast is considered essential for a balanced diet, it has been associated with many positive effects such as the improvement of the nutritional status, increased academic performance [19, 11], reduced mental stress [8] and higher energy and activity levels, [2].

In this regard, one of the problems of public health and health education is the gradual disintegration of eating habits [9]. This is particularly evident among adolescents in practices such as skipping or having less for breakfast. The impact of skipping breakfast is not insignificant. Multiple investigations suggest that this behaviour increases the risk of obesity among young adults, [20] and is linked, among other things, to an increased consumption of energy-dense snacks and higher cholesterol levels [16, 17]. In studies with adolescent girls it has shown to be a symptom of eating disorders and eating-related problems, [13].

The main objective of this study is to ascertain how children and adolescents from multicultural contexts in Southern Spain eat breakfast.

Several studies (AVENA, in KID, SUN, AFINOS) have been developed in Spain to find out about the dietary habits of adolescents and assess their nutritional status. Once again, studies confirm that those young people living in Spain who have breakfast have a lower prevalence of overweight and obesity, $[4,7]$ and women tend to skip breakfast more than men [4, 5 and 12]. Variations have been observed regarding the frequency of skipping breakfast: [18] recorded that 5\% of adolescents in Santander skipped breakfast [1], 17.3\% do eat breakfast daily in Navarra, $18.5 \%$ in Galicia, [3].

\section{Objectives}

The objectives of the study are as follows:

1. Find out which foods children and young adults eat at breakfast and the variety of food they eat depending on whether they have it at home or at midmorning.

2. Determine the foods eaten at breakfast according to gender.

3. Assess the association between having breakfast every morning with feeling fit and energised.

\section{Methodology}

\subsection{Sample}

The sample was constituted by 2.125 children and adolescents living in the Southeast of Spain. The students were aged between 10 and 19, with a mean age of 14.4 years. Regarding gender, $51.3 \%$ are women and $48.7 \%$ men. The students of this sample come from 44 different countries. The most represented nationalities are: Spanish $62.4 \%$, Moroccan 17.5\% and Romanian 7.5\%. Followed by Ecuador, 2.7\%; Guinea Bissau, 2.2\%; 
and Lithuania and England, 1.2\% respectively. The other nationalities do not represent more than $0.6 \%$. $7.7 \%$ of the sample are students from 5 th and 6 th year of primary education, $40.4 \%$ are in 1 st and 2nd year of ESO (Compulsory Secondary Education), $47.1 \%$ are in the $3 \mathrm{rd}$ and 4 th of ESO and $4,9 \%$ from 1 st and 2 nd year of secondary education.

$87 \%$ of students do not suffer from any disease or other medical problems. The remaining $13 \%$ claimed they had an illness, the most representative are asthma and allergies, $6.2 \%$; other diseases to complete 63 are not more than $0.7 \%$. Therefore, the perception that the students from the sample have regarding their health is good. $24.1 \%$ believe that they are in excellent health, $36 \%$ very good, $32.5 \%$ good, $6.6 \%$ average and only $0.7 \%$ consider being in poor health.

\subsection{Instrument}

The KIDSCREEN-27 questionnaire that assesses 10 dimensions of health and quality of life was used, [15]. The response pattern is formulated according to the Likert scale in order to assess the frequency or intensity of each aspect addressed. Numerous studies have validated the survey cross-culturally, [14]. Specifically, this research focuses on the section related to breakfast.

\subsection{Procedure}

It is a cross-sectional randomised study by clusters and by schools. With the support of the Department of Education the schools with the highest proportion of immigrant students were selected. The schools where the questionnaire would be applied were selected from the centres list.

\subsection{Data Analysis}

The data were analysed with the statistical analysis program SPSS version 21. Given the data characteristics percentage calculations were made. Differential calculations are performed using the statistical chi-square $\left(\chi^{2}\right)$.

\section{Results}

\subsection{Breakfast consumption in adolescence}

Breakfast is one of the meals considered to be essential for everyone but especially for young adults given the high levels of energy consumed daily, particularly during the school years.

Young people show different behaviours in relation to this practice. $65.05 \%$ of them usually have breakfast before leaving home; $43.45 \%$ of them also eat breakfast for a second time around noon and $10.4 \%$ eat a second breakfast 4-6 times a week. There is an alarming figure albeit low of cases where teenagers leave home without having breakfast but have mid morning breakfast, 5.7\%; others, $1.5 \%$ have mid-morning breakfast 4-6 times a week. There is a worrying figure, though low, of adolescents who always leave home skipping breakfast but then eat at midmorning 1 or 3 times a week, 2.5\%. Furthermore, we have observed that there are some students, $1.8 \%$ who do not eat breakfast before leaving home nor at midmorning. In relation to those students who skip breakfast throughout the morning we know that 15 are of Spanish origin, 3 are of Moroccan origin and 5 are Romanian; the 
rest belong to other nationalities. Nor do we know whether they do not intake any food throughout the morning by choice or due to a lack of financial means from their families, that is, due to poverty.

Table 1. Contingency table. Breakfast before leaving home / late breakfast

\begin{tabular}{cccccc}
\hline & & \multicolumn{4}{c}{ Late Breakfast } \\
\cline { 3 - 6 } & Every day & $\begin{array}{c}4 \text { to } 6 \\
\text { times/week }\end{array}$ & $\begin{array}{c}1 \text { to } 3 \text { times/ } \\
\text { week }\end{array}$ & Never \\
\hline Breakfast & Every day & $43,45 \%$ & $10,4 \%$ & $6,5 \%$ & $4,7 \%$ \\
before & 4 to 6 times/week & $4 \%$ & $2,3 \%$ & $2,3 \%$ & $0,3 \%$ \\
leaving & 1 to 3 times/week & $6,8 \%$ & $2,8 \%$ & $3,4 \%$ & $1,7 \%$ \\
home & Never & $5,7 \%$ & $1,5 \%$ & $2,5 \%$ & $1,8 \%$ \\
\hline \multicolumn{2}{c}{$\chi^{2}=124,214, p=0.000$} & & &
\end{tabular}

The types of foods that teenagers tend to eat are varied but differ in the proportion in which they are ingested. The foods most often consumed are dairy (milk and yogurt), $72.1 \%$ and bread and cereals by $65.5 \%$; followed by fruit juices $44.9 \%$ and biscuits and pastries $43.7 \%$.

Frequencies in food intake at breakfast. Differences in terms of times a week adolescents eat breakfast before leaving home and when they do so at midmorning.

Adolescents who eat breakfast before leaving home usually do so mostly every day and there are significant differences in relation to the type of food intake when compared to the other two options. The foods consumed the most by adolescents are dairy, bread and cereals, fruits and juices and cocoa or chocolate. If the number of times breakfast is eaten before leaving home is decreased the foods in order would be dairy, bread and cereals, juice and fruit and, fourthly, biscuits and pastries which increase as a percentage as the number of times breakfast is consumed before leaving home decreases.

Table 2. Type of food eaten at breakfast

\begin{tabular}{lc}
\hline \multicolumn{1}{c}{ Food } & Percentage $\%$ \\
\hline Milk and/or yogurt & 72,1 \\
Coffee or Tea & 20,5 \\
Fruit and/or juice & 44,9 \\
Bread or cereals & 65,5 \\
Biscuits and/or Pastries & 43,7 \\
Cheese and/or ham & 14,9 \\
Butter or oil & 30,5 \\
Marmalade & 23,7 \\
Cocoa or Chocolate & 35 \\
\hline
\end{tabular}

Before analysing the types of food that adolescents tend to eat for mid morning breakfast we have to remember that $43.45 \%$ of students in this study eat breakfast every day before leaving home and do so once again at mid morning. The most common foods consumed at mid morning are dairy, bread and cereals and biscuits or pastries and juices. 
Table 3. Frequency of adolescents who eat breakfast before leaving home and statistical Chi-square

\begin{tabular}{llllll}
\hline $\begin{array}{l}\text { Food /Times per week they have } \\
\text { breakfast before they leave home }\end{array}$ & $\begin{array}{l}\text { Every } \\
\text { day }\end{array}$ & $\begin{array}{l}4 \text { to } 6 \text { times } \\
\text { per week }\end{array}$ & $\begin{array}{l}1 \text { to } 3 \text { times } \\
\text { per week }\end{array}$ & $\chi^{2}$ & $p$ \\
\hline Milk and/or yogurt & 1153 & 139 & 193 & 502,36 & 0.000 \\
Coffee or Tea & 270 & 59 & 77 & 32,329 & 0.000 \\
Fruit and/or juice & 644 & 108 & 153 & 94,999 & 0.000 \\
Bread or cereals & 1008 & 139 & 194 & 295,615 & 0.000 \\
Biscuits and/or Pastries & 650 & 96 & 156 & 141,140 & 0.000 \\
Cheese and/or ham & 213 & 36 & 51 & 21,423 & 0.000 \\
Butter or oil & 489 & 57 & 81 & 86,138 & 0.000 \\
Marmalade & 362 & 46 & 72 & 35,341 & 0.000 \\
Cocoa or Chocolate & 524 & 85 & 106 & 81,712 & 0.000 \\
\hline
\end{tabular}

$* p<.05 ; * * p<.000$

Table 4. Frequency of adolescents who have a late breakfast and Chi-square test

\begin{tabular}{llllll}
\hline $\begin{array}{l}\text { Food / Times per week they } \\
\text { have breakfast before they } \\
\text { leave home }\end{array}$ & $\begin{array}{l}\text { Every } \\
\text { day }\end{array}$ & $\begin{array}{l}4 \text { to } 6 \text { times } \\
\text { per week }\end{array}$ & $\begin{array}{l}1 \text { to } 3 \text { times } \\
\text { per week }\end{array}$ & $\chi^{2}$ & $p$ \\
\hline $\begin{array}{l}\text { Milk and/or yogurt } \\
\text { Coffee or Tea }\end{array}$ & 923 & 261 & 194 & 25,610 & 0.000 \\
Fruit and/or juice & 232 & 71 & 72 & 4,150 & 0.246 \\
Bread or cereals & 573 & 145 & 132 & 4,587 & 0.203 \\
Biscuits and/or Pastries & 838 & 233 & 177 & 13,855 & 0.003 \\
Cheese and/or ham & 578 & 145 & 127 & 20,105 & 0.000 \\
Butter or oil & 206 & 42 & 38 & 7,755 & 0.051 \\
Marmalade & 389 & 103 & 82 & 2,414 & 4,158 \\
Cocoa or Chocolate & 296 & 80 & 74 & 4,158 & 0.245 \\
$* p<.05 ; * * * .000$ & 452 & 117 & 102 & 10,663 & 0.014 \\
\hline
\end{tabular}

\subsection{Differences according to gender}

When comparing in our study the food male and female adolescents eat at breakfast we observe that women consume less amounts of food than men. In particular, there have been significant differences in the consumption of dairy products, $48.8 \%$ women and $51.2 \%$ male adolescents $(\chi 2=14,937 ; \mathrm{p}=0.000)$; bread and cereals, $48 \%$ of women and $52 \%$ of men $(\chi 2=17,337 ; \mathrm{p}=0.000)$, and also oil and butter, $47.8 \%$ women and $52.2 \%$ men $(\chi 2=$ $4,653 ; \mathrm{p}<0.05)$

Table 5. Foods eaten at breakfast by gender

\begin{tabular}{lllll}
\hline Food & \% Girls & \% Boys & $\chi^{2}$ & $p$ \\
\hline Milk and/or yogurt & 48,8 & 51,2 & 14,937 & 0.000 \\
Coffee or Tea & 47,8 & 52,2 & 2,766 & 0.096 \\
Fruit and/or juice & 49,6 & 50,4 & 1,864 & 0.172 \\
Bread, toast or cereals & 48 & 52 & 17,337 & 0.000 \\
Biscuits and/or Pastries & 49,4 & 50,6 & 2,472 & 0.116 \\
Cheese and/or ham & 48,7 & 51,3 & 0,994 & 0,319 \\
Butter or oil & 47,8 & 52,2 & 4,653 & 0.031 \\
Marmalade & 51,3 & 48,7 & 0,001 & 0.980 \\
Cocoa or Chocolate & 49,7 & 50,3 & 1,291 & 0,256 \\
\hline
\end{tabular}

$* p<.05 ; * * p<.000$ 


\subsection{The association between feeling well and fit and eating breakfast before leaving home}

Having breakfast each morning before leaving home is a healthy habit that helps us to feel good, fit and energetic. We observed among the adolescents in our sample that those who had breakfast every morning before leaving home had better perceptions of themselves and believed to be fit $(\chi 2=132,318$ y $\mathrm{p}=0.000)$.

Table 6. Contingency Table Have you felt fit and well?/ Breakfast before leaving home.

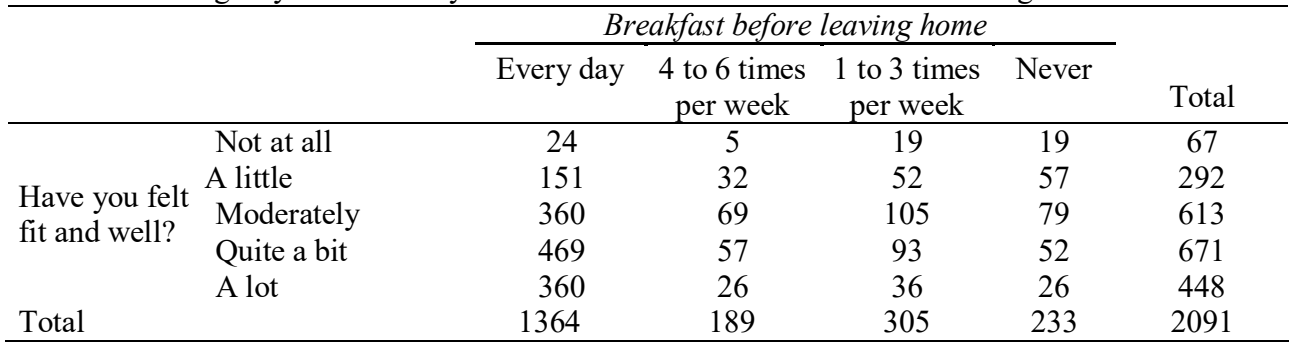

\section{Debate and Conclusions}

We believe that this study has provided interesting findings and the proposed objectives have been achieved. The study sample reflects the cultural diversity that exists in the Southeast of Spain and we have found that a significant number of students, $35 \%$, go to school skipping breakfast. Some of them have a late breakfast but we have observed that those who do so eat more biscuits (sweets) than those who have breakfast before leaving home. Furthermore, it is worrying that $1.8 \%$ of students do not eat anything all morning. It is unclear whether it is due to a bad habit acquired by haste or the thin ideal, or may be due to poverty situations in our society.

Merino, [10] in a study conducted with students in multicultural contexts in the Southeast of Spain found that young children do not eat breakfast or eat very little, namely chocolate milk and, in a minority of cases, solid food. In addition, this research shows that children have breakfast every morning in a hurry, reflecting a fast-paced family life in which bad habits arise such as going to bed late and not having breakfast together as a family.

Furthermore, although dairy products, cereals and juices are the ones consumed the most by students, this intake is done in low percentages considering that breakfast is the main meal of the day.

In relation to the second objective, we note that the women in the study eat fewer types of foods than men and in less quantity and these differences remained significant. We agree with Quiles-Marcos et al [13] that this is due to the concern that adolescents manifest regarding their body and the desire to be thin, which can lead to eating disorders if educational programs on food and nutrition are not put in place.

We express concern over the results where it is evident that as the adolescent leaves home skipping breakfast and eats breakfast just a few times a week only at around noon the consumption of sweets increases, which leads to bad habits that can cause obesity as shown in studies by $[20,16]$.

Lastly, in relation to the third objective we have found a connection between eating breakfast every morning and the student's perception of feeling energised and fit. Our results are consistent with the findings from the [2] studies. 


\section{Conclusions}

1. There are many students who enter the classroom every day having skipped breakfast.

2. Adolescent girls eat less food and less quantity than men.

3. Pupils who have breakfast each morning before leaving home feel more energetic and fit.

4. We suggest making time for breakfast, parents should lead by example and educate families to begin the day calmly, together as a family seated around the table enjoying breakfast.

\section{References}

1. Ayechu, A., \& Durá, T., Calidad de los hábitos alimentarios (adherencia a la dieta mediterránea) en los alumnos de educación secundaria obligatoria. Anuario del Sistema Sanitario de Navarra, 33(1), 35-42, (2010).

2. Chitra, U., \& Reddy, C. R., The role of breakfast in nutrient intake of urban school children. Public Health Nutrition, 10, 55-63, (2007).

3. De la Montaña, J., Castro, L., Cobas, N., Rodríguez, M., \& Míguez, M., Adherencia a la dieta mediterranea y su relación con el índice de masa corporal en universitarios de Galicia. Nutrición Clínica y Dietética Hospitalaria, 32(3), 72-80, (2012).

4. Díez-Navarro, A., Martín-Camargo, A., Solé-Llussà, A., Gnzález-Montero, M., \& Marrodán, M. D., Influencia del desayuno sobre el exceso ponderal en población infantil y adolescente de Madrid. Nutrición clínica y dietética hospitalaria, 34(2), 9-17. (2014).

5. Fernández Morales, I., Aguilar Vilas, M. V., Mateos Vega, C. J., \& Martínez Para, M. C., Breakfast quality and its relationship to the prevalence of overweight and obesity in adolescents in Guadalajara (Spain). Nutrición Hospitalaria, 26(5), 952-958, (2011).

6. Galiano Segovia, M. J., \& Moreno Villares, J. M., El desayuno en la infancia: más que una buena costumbre. Acta Pediatrica España, 68(8), 403-408, (2010).

7. Henríquez Sánchez, P., Doreste Alonso, J., Laínez Sevillano, P., Estévez González, M. D., Iglesias Valle, M., Martín López, G., . . . Serra Majem, L., Prevalencia de obesidad y sobrepeso en adolescentes canarios. Relación con el desayuno y la actividad física. Medicina Clinica, 130(1), 606-10, (2008).

8. Lien, L., Is breakfast consumption related to mental distress and academic performance in adolescents? Public Health Nutrition, 10(4), 422-428, (2006).

9. Lytle, L. A., Seifert, Greenstein, J., \& McGovern, p., How do children's eating patterns and food choices change over time? Results from a cohort study. American Journal of Health Promotion, 14(4), 222-228, (2000).

10. Merino, M.A., Descubriendo los hábitos alimenticios en la escuela multicultural a través de los debates infantiles. Index de enfermeria, 17(3), 183-1187, (2008).

11. Powell, C. A., Walker, S. P., Chang, S. M., \& Grantham-McGregor, M., Nutrition and education: a randomized trial of the effects of breakfast in rural primary school children. American Journal of Clinical Nutrition, 68, 873-879, (1998).

12. Prado , C., Rovillé-Sausse, F., Marrodan, D., Muñoz, B., Fernández del Olmo, R., \& Calabria, V., Situación somatofisiológica y nutricional de los jóvenes inmigrantes en España. Variación según género y procedencia. Archivos Latinoamericanos de Nutrición, 367-373, (2011).

13. Quiles-Marcos, Y., Balaguer-Solá, I., Pamies-Aubalat, L., Quiles-Sebastián, M. J., Marzo-Campos, J. C., \& Rodríguez-Marín, J., Eating Habits, Physical Activity, Consumption of Substances and Eating Disorders in Adolescents. The Spanish Journal of Psychology, 14(2), 712-723, (2011). 
14. Ravens-Sieberer, U., Gosch, A., Rajmil, L., Erhart, M., Bruil, J., Power, M., . . . KIDSCREEN , G., The KIDSCREEN-52 Quality of Life Measure for Children and Adolescents: Psychometric Results from a Cross-Cultural Survey in 13 European Countries. Value in health, 11(4), 645-658, (2008).

15. Ravens-Sieverer, U., Auquier, P., Erhart, M., Gosch, A., Ramjil, L., Bruil, J., \& et, a. , The KIDSCREEN-27 quality of life measure for children and adolescents: psychometric results from a cross-cultural survey in 13 European countries. Quality of Life Research(16), 1347-1356, (2007).

16. Renzaho, A., Swinburn, B., \& Burns, C., Maintenance of traditional cultural orientation is associated with lower rates of obesity and sedentary behaviours among African migrant children to Australia. International Journal of Obesity, 32, 594-600, (2008).

17. Resnicow, K., The relationship between breakfast habits and plasma cholesterol levels in school children. Journal of School Health, 61(2), 81-95, (1991).

18. Rufino, P., Redondo, C., Amigo, T., Gonzalez-Lamuño, D., García, M., \& grupo AVENA., Desayuno y almuerzo de los adolescentes escolarizados de Santander. Nutrición Hospitalaria, 217-222, (2005).

19. Sánchez Hernández, J. A., Importancia del desayuno en el rendimiento intelectual y en el estado nutricional de los escolares. Revista Española de Nutrición Comunitaria, 6(2), 53-95, (2000).

20. Thompson-McCormick, J. J., Thomas , j. J., Bainivualiku, A., Khan, A. N., \& Becker, A. E., Breakfast skipping as a risk correlate of overweight and obesity in school-going ethnic Fijian adolescent girls. Asia Pacific Journal of Clinical Nutrition, 19(3), 372$382,(2010)$. 